\title{
Inflammatory Cells in Tissues of Gout Patients and Their Correlations with Comorbidities
}

\author{
Syeling Lai ${ }^{1,2}$ and Xiaodong Zhou ${ }^{*}, 3$ \\ ${ }^{I}$ Department of Pathology, Baylor College of Medicine, One Baylor Plaza, Houston, TX 77030, USA \\ ${ }^{2}$ Department of Pathology, Michael E. DeBakey VA Medical Center, 2002 Holcombe Blvd, Houston, TX 77030, USA \\ ${ }^{3}$ Department of Internal Medicine, University of Texas Health Science Center at Houston, 6431 Fannin, Houston, TX \\ 77030, USA
}

\begin{abstract}
Background: The major pathological finding of gout is the deposition of monosodium urate monohydrate (MSU) crystals with inflammatory infiltrate in the tissue. There have been many reports of in vitro analysis of inflammatory mechanism and comorbidities in gout. However, the associations of immune response cells and comorbidities of gout have not been well documented. Our studies aimed to examine the immune cell types and quantity in gout tissues, and to define the association of individual cell type with comorbidities.

Methods: Surgically resected or biopsied tissues from 48 patients diagnosed as gout were used for this study. Cell count was performed on Hemotoxylin and Eosin stained sections for macrophages, plasma cells, neutrophils and on immunostained slides for $\mathrm{T}$ and $\mathrm{B}$ lymphocytes.

Results: Hyperlipidemia, hypertension and diabetes mellitus were seen in $70.8 \%, 87.5 \%$ and $37.5 \%$ of patients, respectively. There were $35.6 \%$ and $37.8 \%$ of patients who admitted history of smoking and alcohol intake, respectively. Mean serum uric acid level was $8.5 \mathrm{mg} / \mathrm{dl}$. The average body mass index was $30.1 \mathrm{~kg} / \mathrm{m}^{2}$. H\&E stained tissue sections demonstrated the crystalline deposits rimmed by palisading multinucleated giant cells, macrophages, neutrophils, plasma cells, T and B cells. Significant correlations between the clinical features and tissue inflammatory cells were observed in hyperlipidemia with number of T cells $(p=0.0363)$, hypertension with number of T cells and B cells $(p=0.0138$ and 0.0033 , respectively), diabetes mellitus with macrophages $(p=0.0016)$, and uric acid level with giant cells $(p=0.0088)$.

Conclusion: Comorbidity factors including hyperlipidemia, hypertension and diabetes are significantly associated with the inflammatory cells in the tissues.
\end{abstract}

Keywords: Gout, mononucleated macrophages, multinucleated giant cells, T-cells, B-cells, uric acid, comorbidities.

\section{INTRODUCTION}

Gout is a chronic arthritis resulting from an inflammatory response to monosodium urate (MSU) crystals in the tissues. It affects $1 \%$ of population with majority being male patients [1-4]. Gout is characterized by elevated serum uric acid level leading to the formation and accumulation of synovial fluid crystals which mediate chronic inflammation. MSU may crystallize when plasma concentration exceeds its solubility (around $7 \mathrm{mg} / \mathrm{dl}$ ), which is considered as critical concentration for onset of gout [5,6]. The participating inflammatory cells in the tissues include predominantly Tlymphocyte, some macrophages, foreign body multinucleated giant cells and less commonly B-lymphocyte, neutrophils and plasma cells [7]. These together with their cellular products such as a variety of chemokines progressively destroy the cartilage and may cause osteolytic irregular destruction of subchondral bone $[3,8]$. These

*Address correspondence to this author at the Department of Internal Medicine, University of Texas Health Science Center at Houston, 6431 Fannin, Houston, TX 77030, USA; Tel: 713-500-6900; Fax: 713-500-0580; E-mail: xiaodong.zhou@uth.tmc.edu deposits may extend out from a joint into the soft tissue and cause destruction of the ligaments. This destruction eventually leads to subcutaneous deposits that may erode through the skin. When there is an intense, self-limited bout of acute arthritis with excruciating pain, the patients present as an attack of gout clinically. The hyperuricemia may be caused by diet, increased breakdown associated with malignancy, decreased renal excretion or genetic factors. Reported contributing factors also include hypertension, abnormal lipid metabolism, renal dysfunction, and the use of diuretics [9].

Understanding the inflammatory nature of uric acid crystals is essential to gain insight into the pathogenic mechanism of gout. There are emerging lines of evidence of immunologic responses contributing to the mechanisms and processes involved in MSU-mediated adjuvanticity and inflammation in vitro experimental models in the last decades $[7,10]$. However, only few studies of in vivo tissue examination for the cellular characterizations were published [7]. In this study, we examined cell types in gout specimen and defined risk factors and comorbidities in corresponding 
veteran male patients. We finally analyzed the association of individual cell type with comorbidities.

\section{MATERIALS AND METHODS}

\section{Specimens and Clinical Characteristics}

Forty eight patients' specimens previously diagnosed as gout histologically constitute the materials. Patients were enrolled by snomed code search from pathology report data base and review of electronic chart system. Most of the specimens were surgically resected tissues (39 cases), the remainders were biopsy samples (9 cases). Formalin-fixed, paraffin-embedded (FFPE) blocks were made and sections were stained with Hemotoxylin \& Eosin (H\&E) by standard histology protocol. The initial diagnoses of gout were made by clinical physicians, and were rendered by multiple pathologists who were on service in routine practice. All the slides were also reviewed by experienced pathologist to confirm the diagnosis in tissue sections of all cases under transmitted light microscopy during this study. Histological diagnosis of gout was based on the histiocytes and foreign body giant cell reaction to the deposited crystals [4]. Examination of properly preserved tissue sections by the polarized light demonstrated the crystalline nature of the deposit. Surrounding chronic and occasionally acute inflammatory cells may also present. Specimen sites included upper extremities (24 cases), lower extremities (21 cases) and external ear (3 cases). Cases of upper extremities were comprised of hand joint synovial soft tissue (10 cases), elbow joint synovial soft tissue (13 cases) and elbow skin (1 cases). Tissue sources from lower extremities were foot joint synovial soft tissue (15 cases), toe bone ( 3 cases), knee joint synovial soft tissue ( 1 cases) and toe skin ( 2 cases). Tissues of external ear consisted of external ear skin ( 2 cases) and helix skin (1 cases). Uric acid levels and body mass indexes were achieved at or immediately prior to the time specimens were obtained. Hypertension, hyperlipidemia and diabetes were diagnosed by standard clinical guideline. Smoking and drinking history was recorded when the patients continued to have cigarette use and more than occasional alcohol use at the time specimens were obtained. This study was approved by Baylor College of Medicine institutional review board.

\section{Immunohistochemistry}

Paraffin-embedded blocks were cut on slides. The sections were deparaffinized and stained with CD3 antibodies for T-cell and CD20 antibodies for B-cell (Cell Marque, Rocklin, California and Dako, Denmark, California) using Bond Polymer Refine Detection System (Leica Biosystems Newcastle Ltd, Newcastle Upon Tyne NE12 8EW, United Kingdom).

\section{Quantitation of Cells}

$\mathrm{T}$ and $\mathrm{B}$ lymphocytes, neutrophils, mononucleated macrophages, multinucleated giant cells and plasma cells were counted on one slide of every specimen. CD3 positive T-cell and CD20 positive B-cell were differentiated by immunostaining. The remainder cell types were identified by morphology based on H\&E staining. Dense cellular areas were selected and each category of cells was counted in five high power fields (HPF) at $400 \mathrm{X}$ magnification.

\section{Statistical Analysis}

Associations of cell quantitation and clinical data were analyzed by using Pearson correlation, two-tailed probability value, and plotted by box-and-whisker plot. Significant association was cut off at $p<0.05$.

\section{RESULTS}

All 48 patients were male veterans with the mean age of 63 year-old (ranging from 39 to 84). Mean serum uric acid level at the time specimens were submitted was $8.5 \mathrm{mg} / \mathrm{dl}$ (ranging from 5.0 to $14.2 \mathrm{mg} / \mathrm{dl}$ ). Patients with hyperuricemia were in $84.4 \%$ (Table 1). Hyperuricemia was defined as a serum uric acid level higher than $7 \mathrm{mg} / \mathrm{dl}$ in male (uric acid becomes insoluble when its plasma concentration is above it). The mean BMI was $30.1 \mathrm{~kg} / \mathrm{m}^{2}$ (ranging from 17.9 to $45.0 \mathrm{~kg} / \mathrm{m}^{2}$ ). Obesity indicated by BMI $>30 \mathrm{~kg} / \mathrm{m}^{2}$ was suggested in $40.4 \%$ of patients. Hypertension was found in $87.5 \%$ of patients. There were $35.6 \%$ and $37.8 \%$ of patients who admitted history of smoking and alcohol intake, respectively. Hyperlipidemia and diabetes mellitus were seen in $70.8 \%$ and $37.5 \%$ of patients, respectively.

\section{Table 1. Clinical Characteristics of Patients with Gout}

\begin{tabular}{|c|c|c|c|}
\hline Parameters & Value or PRE* & Patients N & Percentage \\
\hline \multirow{2}{*}{$\begin{array}{c}\text { Age (when } \\
\text { specimen was obtained) }\end{array}$} & $\leq 60$ & 19 & $39.6 \%$ \\
\hline & $>60$ & 29 & $60.4 \%$ \\
\hline \multirow{3}{*}{ Uric Acid Level } & $<7 \mathrm{mg} / \mathrm{dl}$ & 7 & $15.6 \%$ \\
\hline & $>7 \mathrm{mg} / \mathrm{dl}$ & 38 & $84.4 \%$ \\
\hline & NA & 3 & \\
\hline \multirow{2}{*}{ BMI } & $<30 \mathrm{~kg} / \mathrm{m}^{2}$ & 28 & $59.6 \%$ \\
\hline & $>30 \mathrm{~kg} / \mathrm{m}^{2}$ & 19 & $40.4 \%$ \\
\hline \multirow{3}{*}{ Smoking } & yes & 16 & $35.6 \%$ \\
\hline & no & 29 & $64.4 \%$ \\
\hline & NA & 3 & \\
\hline \multirow{3}{*}{ Drinking } & yes & 17 & $37.8 \%$ \\
\hline & no & 28 & $62.2 \%$ \\
\hline & NA & 3 & \\
\hline \multirow{2}{*}{ Hypertension } & yes & 42 & $87.5 \%$ \\
\hline & no & 6 & $12.5 \%$ \\
\hline \multirow{2}{*}{ Hyperlipidemia } & yes & 34 & $70.8 \%$ \\
\hline & no & 14 & $29.2 \%$ \\
\hline \multirow{2}{*}{ Diabetes } & yes & 18 & $37.5 \%$ \\
\hline & no & 30 & $62.5 \%$ \\
\hline \multirow{2}{*}{ Diuretic Use } & yes & 15 & $31.2 \%$ \\
\hline & no & 33 & $68.8 \%$ \\
\hline
\end{tabular}


H\&E stained sections of FFPE tissue demonstrated amorphous crystalline deposits rimmed by palisading multinucleated giant cells, macrophages, chronic and occasionally acute inflammatory cells in all cases under transmitted light microscopy (Fig. 1A-C). Polarization of the properly preserved tissue revealed the needle-shaped, double refractile crystals (Fig. 1D). Average cell counts of T-cell, Bcell, multinucleated giant cells, mononucleated macrophages, plasma cells and neutrophils were: $38.6,13.0$, $6.8,31.6,0.7$, and 5.8 cells/HPF, respectively. Their corresponding standard deviations and ranges were 35.6 (5.2-136.6), 19.0 (0-101.8), 5.4 (0.2-20.8), 19.6 (3.4-95.0), $2.5(0-17.0)$ and $14.1(0-72.4)$, respectively. Eosinophils were occasionally seen in rare cases. Fig. $(\mathbf{2 A}, \mathbf{B})$ highlighted $\mathrm{CD} 3$ positive $\mathrm{T}$ lymphocytes and $\mathrm{CD} 20$ positive B lymphocytes by immunohistochemistry.

The correlations of comorbidities of gout and quantitation of immune cell responses were evaluated by statistical significance of $\mathrm{p}$ value (Table 2). Of those significant associations, increased $\mathrm{T}$ cells were correlated in gout patients with hyperlipidemia and hypertension ( $p=$ 0.0363 and 0.0138 , respectively). Increased B cells also were

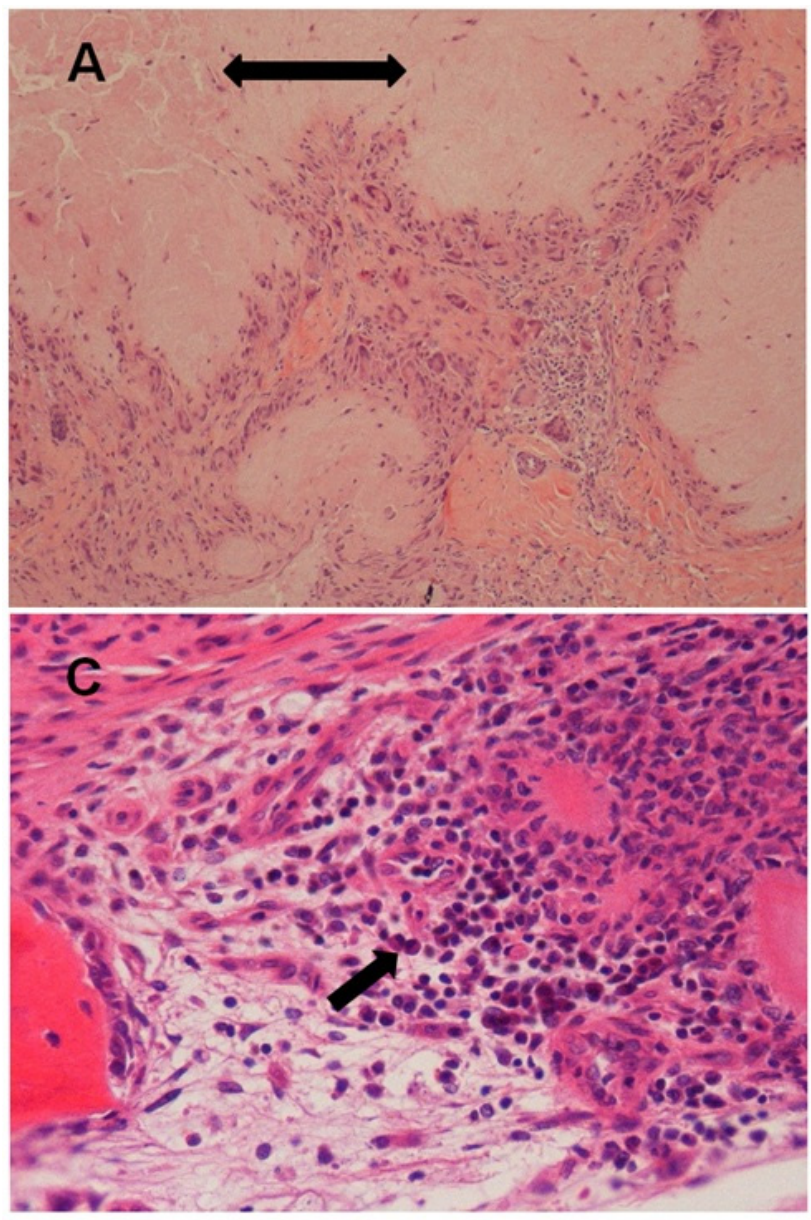

correlated with hypertension $(p=0.0033)$. The presence of diabetes in gout patients was correlated with the decreased number of macrophages in the tissues $(p=0.0016)$. Giant cell count in tissues and the level of uric acid demonstrated a negative correlation $(p=0.0088)$. In addition, increased neutrophils also correlated with hypertension with a marginally significant $\mathrm{p}$-value $(p=0.0535)$. The results of significant associations were illustrated in the Fig. (3) using box plot. The significant $\mathrm{p}$-value after correction for multiple comparisons was 0.0071 .

\section{DISCUSSION}

Although studies of pathogenesis of gout are ample, in vivo quantitation of inflammatory cells and analysis of their associations with comorbidity are rarely reported. Our study showed that in gout tissue sections, majority of inflammatory cells were T-lymphocyte, macrophages and foreign body giant cells. B-lymphocyte and plasma cells with scattered neutrophils also presented in the tissues. Importantly, the presence of hypertension in patients with gout appeared to significantly correlate with increased $\mathrm{T}$ and $\mathrm{B}$ lymphocytes in gout tissues. It also showed a marginal significant correlation with enriched neutrophils. The presence of
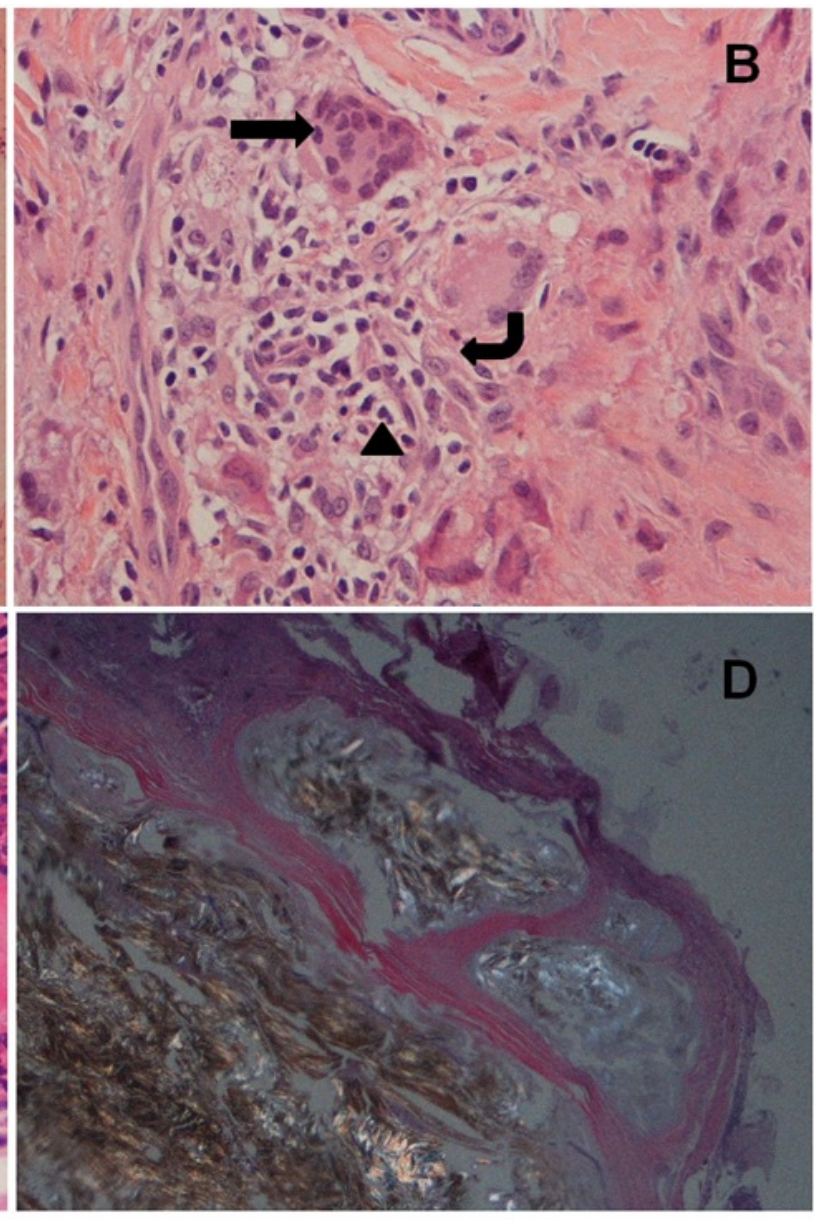

Fig. (1). Examples of the tissue from patients with gout. (A) H\&E section shows central amorphous material (double head arrow) rimmed by multinucleated giant cells and inflammatory cells, and surrounded by soft tissue (100X magnification); (B) Multinucleated giant cells (arrow), macrophages (angular arrow) and neutrophils (arrow head) (400X); (C) Amorphous material and inflammatory cells including rare plasma cells (arrow) in bone marrow (400X); (D) Polarized light microscopy demonstrates strongly negatively birefringent needle-shaped crystals and surrounding fibrous tissue (100X). Of note, hand joint synovial soft tissues were showed in (A, B, C); foot joint synovial soft tissue was shown in (D). 
hyperlipidemia also was correlated with increased $\mathrm{T}$ lymphocyte counts in gout tissues. On the other hand, negative correlations were found between diabetes in gout patients and macrophages in the tissues, as well as hyperuricemia and giant cell count in tissues.

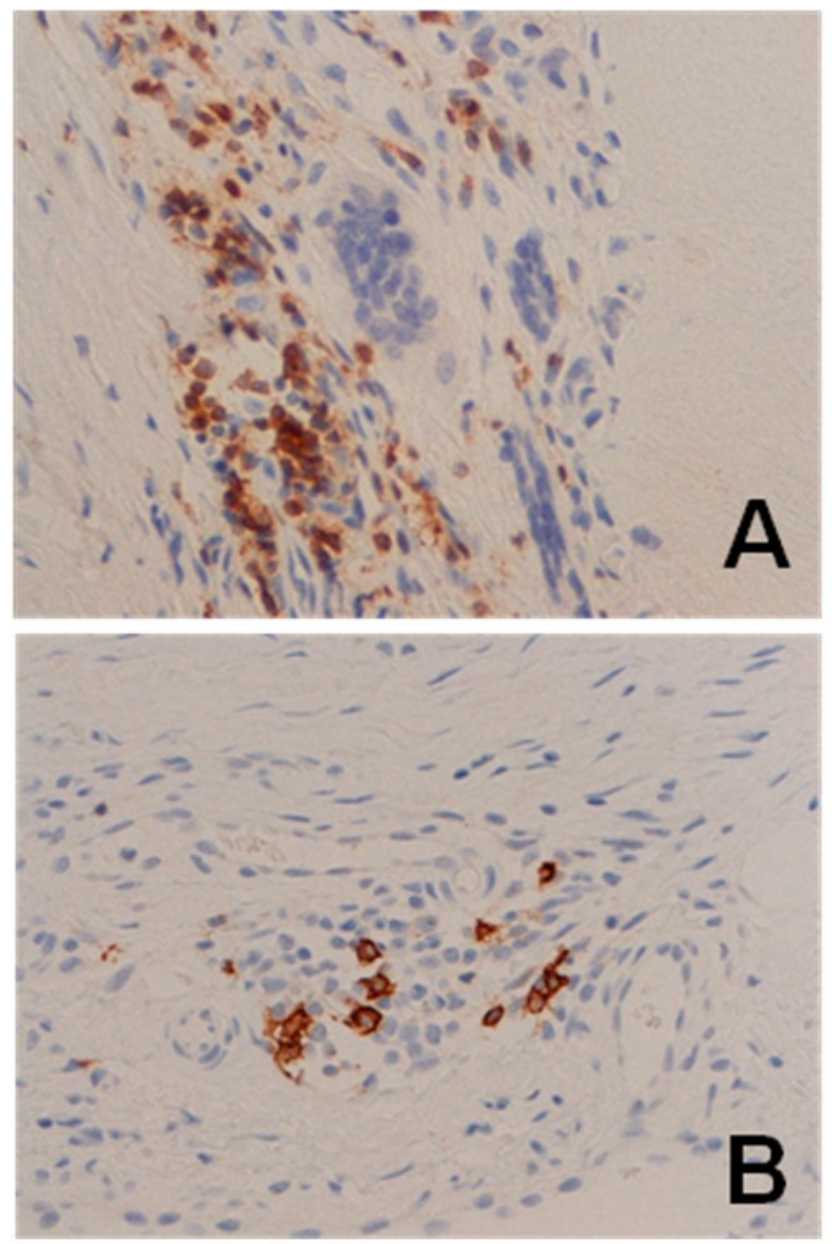

Fig. (2). Examples of elbow joint synovial soft tissues with immunostaining of lymphocytes. (A) Diffuse CD3 staining of Tlymphocyte; (B) Rare CD20 staining of B-lymphocyte.

It is commonly known that deposition of MSU crystals in the tissues provokes gout by activating leukocytes and induce inflammatory responses. Degree of inflammatory responses in gout can be affected by interactions between MSU microcrystals and the local tissue environment [5]. The formation of MSU crystals is facilitated by hyperuricemia. However, not all patients with hyperuricemia develop gout. The development of gout is potentially attributable to both local burden on MSU crystals and general body condition. The observation of a significantly decreased giant cells in gout patients with hyperuricemia is of interesting, but need further confirmation.

Multiple factors such as injuries, cold, food intake and heavy wine drinking that change body condition may provoke acute attack of gout [9]. Comorbidities such as hypertension, diabetes, obesity and hyperlipidemia may impact overall health condition of gout patients as well as treatment strategies. Studies of gout indicated that increased frequency of hypertension was associated with the duration of gout suggesting that poor control of gout is one of the causes of hypertension [9]. Other studies also showed uric acid predicted hypertension [9,11-13]. Our observation of a positive correlation between hypertension and $\mathrm{T} / \mathrm{B}$ lymphocytes suggests that inflammatory cells may play important roles in hypertension associated gout. Whether gout can impact hypertension through inflammatory process in the body, and/or on the other hand, hypertension predisposes local burden attributing to inflammatory cell response in gout tissues is still unclear.

Diabetes and hyperlipidemia also frequently present in gout patients [14-16]. However, diabetes was reported to protect patients from future risk of gout [14]. A decreased amount of macrophages in the tissues of gout patients with diabetes seemed an interesting presentation in correlation with this report. A positive correlation between hyperlipidemia and $\mathrm{T}$ lymphocytes supports a notion that metabolic alterations like hyperlipidemia might promote $\mathrm{T}$ cells infiltration of inflammatory sites by modifying their intracellular metabolism [17].

Characterization of comorbidities and immune response cells in gout is valuable for future studying pathogenesis of gout, as well as for a better patient management. Our understanding of the mechanism of any association between them is far from complete. The mechanisms of association between comorbidities and immune cell responses remain to be identified in future studies.

Table 2. Correlation of Comorbidities of Gout and Immune Cell Types by $p$ Value

\begin{tabular}{|c|c|c|c|c|c|c|c|}
\hline & \multicolumn{7}{|c|}{ Clinical Features } \\
\cline { 2 - 8 } & Hyperlipidemia & Hypertension & Uric Acid & Diabetes & BMI & Smoking & Drinking \\
\hline \hline T cells & 0.0363 & 0.0138 & 0.9360 & 0.2004 & 0.2056 & 0.6980 & 0.9207 \\
\hline B cells & 0.7246 & 0.0033 & 0.9514 & 0.1576 & 0.4019 & 0.7817 & 0.6476 \\
\hline Giant cells & 0.3299 & 0.1702 & 0.0088 & 0.3528 & 0.1500 & 0.4883 & 0.4734 \\
\hline Macrophages & 0.9982 & 0.8518 & 0.4360 & 0.0016 & 0.3666 & 0.5838 & 0.8607 \\
\hline Plasma cells & 0.4070 & 0.4241 & 0.2964 & 0.5014 & 0.4670 & 0.2810 & 0.7397 \\
\hline Neutrophils & 0.3189 & 0.0535 & 0.1041 & 0.1427 & 0.8371 & 0.4858 & 0.3384 \\
\hline Uric Acid & 0.9579 & 0.8454 & NA & 0.3068 & 0.7471 & 0.3163 & 0.6015 \\
\hline
\end{tabular}



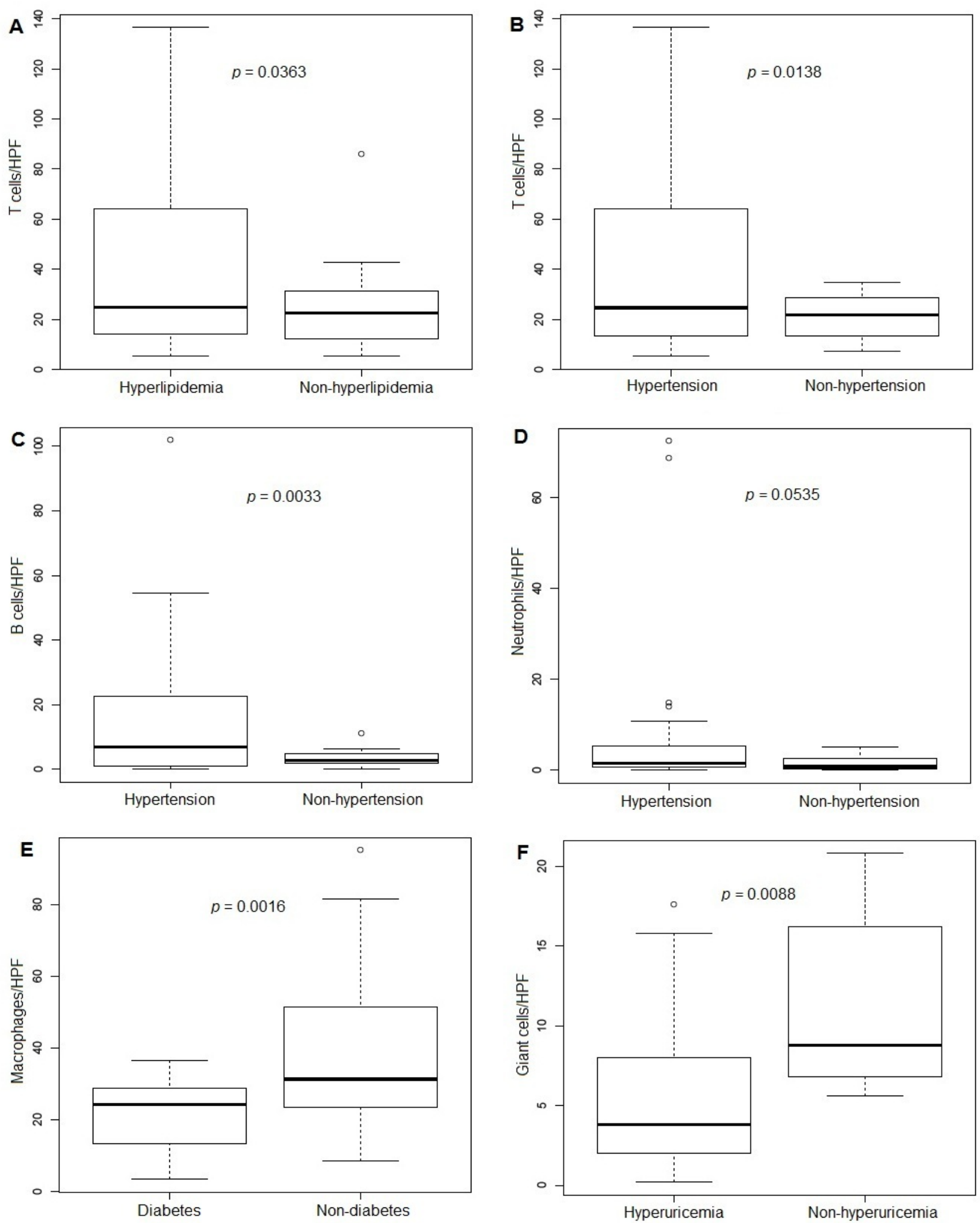

Fig. (3). Association between inflammatory cells, uric acid levels and comorbidities. (A) $\mathrm{T}$ cells and hyperlipidemia; (B) $\mathrm{T}$ cells and hypertension; (C) B cells and hypertension; (D) Neutrophils and hypertension; (E) Macrophages and diabetes; (F) Giant cells and hyperuricemia. *The line inside the box indicates median value, the box shows 25 th and 75 th percentiles, the bars indicate 10 th and 90 th percentiles, and the circles stand for outliers. 


\section{ABBREVIATIONS}

$$
\begin{aligned}
& \text { MSU }=\text { Monosodium urate } \\
& \text { FFPE }=\text { Formalin-fixed, paraffin-embedded } \\
& \mathrm{H \& E}=\text { Hemotoxylin \& Eosin } \\
& \mathrm{HPF}=\text { High power fields }
\end{aligned}
$$

\section{CONFLICT OF INTEREST}

The authors confirm that this article content has no conflict of interest.

\section{ACKNOWLEDGEMENTS}

Declared none.

\section{REFERENCES}

[1] Martinon F. Update on biology: uric acid and the activation of immune and inflammatory cells. Curr Rheumatol Rep 2010; 12: $135-41$.

[2] Richette P, Bardin T. Gout. Lancet 2010; 375: 318-28.

[3] Shi Y, Mucsi AD, Ng G. Monosodium urate crystals in inflammation and immunity. Immunol Rev 2010; 233: 203-17.

[4] Rosai J. Rosai and Ackerman's Surgical Pathology. $9^{\text {th }}$ ed. China: Mosby an affiliate of Elsevier 2004

[5] Busso N, So A. Mechanisms of inflammation in gout. Arthritis Res Ther 2010; 12: 206.

[6] Fiddis RW, Vlachos N, Calvert PD. Studies of urate crystallisation in relation to gout. Ann Rheum Dis 1983; 42: 12-5.
[7] Dalbeth N, Pool B, Gamble GD, et al. Cellular characterization of the gouty tophus: a quantitative analysis. Arthritis Rheum 2010; 62: 1549-56.

[8] Harre U, Derer A, Schorn C, Schett G, Herrmann M. T cells as key players for bone destruction in gouty arthritis. Arthritis Res Ther 2011; 13: 135 .

[9] Ichikawa N, Taniguchi A, Urano W, Nakajima A, Yamanaka H Comorbidities in patients with gout. Nucleosides Nucleotides Nucleic Acids 2011; 30: 1045-50.

[10] Dalbeth N, Haskard DO. Mechanisms of inflammation in gout. Rheumatology (Oxford) 2005; 44: 1090-6.

[11] Nagahama K, Inoue T, Iseki K, et al. Hyperuricemia as a predictor of hypertension in a screened cohort in Okinawa, Japan. Hypertens Res 2004; 27: 835-41.

[12] Webb R, Jeffries M, Sawalha AH. Uric acid directly promotes human T-cell activation Am J Med Sci 2009; 337: 23-7.

[13] Oparil S, Zaman MA, Calhoun DA. Pathogenesis of hypertension. Ann Intern Med 2003; 139: 761-76.

[14] Liu Q, Gamble G, Pickering K, Morton S, Dalbeth N. Prevalence and clinical factors associated with gout in patients with diabetes and prediabetes. Rheumatology (Oxford) 2012; 5: 757-9.

[15] Feldman EB, Wallace SL. Hypertriglyceridemia in gout. Circulation 1964; $29: 508-13$

[16] Jiao S, Kameda K, Matsuzawa Y, Tarui S. Hyperlipoproteinaemia in primary gout: hyperlipoproteinaemic phenotype and influence of alcohol intake and obesity in Japan. Ann Rheum Dis 1986; 45: 30813.

[17] Mauro C, Marelli-Berg FM. T cell immunity and cardiovascular metabolic disorders: does metabolism fuel inflammation? Front Immunol 2012; 3: 173 .

(C) Lai and Zhou; Licensee Bentham Open.

This is an open access article licensed under the terms of the Creative Commons Attribution Non-Commercial License (http://creativecommons.org/licenses/by-nc/ $3.0 /$ ) which permits unrestricted, non-commercial use, distribution and reproduction in any medium, provided the work is properly cited. 